\title{
Determinants of Hypertension Complications Among Adult Hypertensive Patients in Medical Wards at Kenyatta National Hospital, Nairobi
}

\author{
Isiaho Lillian Amugitsi ${ }^{*}$, Ayieko A. O., Omuga B. O.
}

School of Nursing sciences University of Nairobi, Kenya

Email address:

lilianisiaho@gmail.com (Isiaho L. A.)

${ }^{*}$ Corresponding author

\section{To cite this article:}

Isiaho Lillian Amugitsi, Ayieko A. O., Omuga B. O. Determinants of Hypertension Complications Among Adult Hypertensive Patients in Medical Wards at Kenyatta National Hospital, Nairobi. American Journal of Nursing Science. Vol. 5, No. 5, 2016, pp. $213-221$. doi: 10.11648/j.ajns.20160505.16

Received: September 17, 2016; Accepted: September 27, 2016; Published: October 26, 2016

\begin{abstract}
Hypertension is a silent killer disease owing to the late recognition of symptoms. Uncontrolled hypertension is the primary risk factor for stroke, heart failure and kidney failure in sub Saharan Africa. Control of hypertension is associated with a larger reduction in morbidity and mortality. Efforts to address the complications associated with hypertension are still a global concern. In sub Saharan Africa the epidemiological transition of non communicable diseases poses a great threat to most of the population. The main aim of this study was to identify the determinants of hypertension complications among hypertensive patients in Kenyatta National Hospital. A cross sectional descriptive design among eighty hypertensive patients in medical wards in Kenyatta National Hospital was conducted. Data was collected using structured questionnaires, key informants interviews and focused group discussions. 34 (42.5\%) participants were already suffering hypertension complications at the time of the study. The mean age of participants was 49.7 years (SD 15.1). There was a significant association between current systolic blood pressure $(p=0.033)$, adding salt to food $(p=0.01)$, level of education $(p=0.001)$ and hypertension complication. Finances and lack of adequate knowledge were main factors cited to be contributing to development of hypertension complications among in the key informants interviews and Focused Group Discussion.
\end{abstract}

Keywords: Hypertension, Determinants, Hypertension Complications, Kenyatta National Hospital (KNH)

\section{Introduction}

\subsection{Background}

Contemporary literatures have revealed that hypertension complications are a growing public health problem in many countries [1]. In KNH the number of patients being admitted with hypertension complications is high, from the statistics obtained from the Health Information Systems department, in 2014 the number of patients admitted with hypertension related complication to include renal failure, congestive heart failure, and those with unspecified secondary hypertension was four hundred and ninety two, two hundred and fifty two of whom succumbed to death, this basically means that $51 \%$ of the admitted hypertensive patients succumbed.

Hypertension was initially associated with the developed countries but currently the condition is increasingly emerging in low and middle-income countries (LMICs) where health resources are scarce and those available are stretched by a high burden of infectious diseases and where awareness and treatment levels on hypertension control are still very low thereby predisposing the hypertensive patients to complications.

\subsection{Statement of the Problem}

According to the global brief on hypertension report, hypertension contributes to the burden of heart disease, stroke and kidney failure and is the cause of premature mortality and disability. Hypertension remains uncontrolled in many developing and developed countries.

In the wake of epidemiological transition of non communicable disease in sub Saharan Africa, the mortality 
and morbidity from non communicable diseases in the low and middle class countries Kenya being one of them keeps on increasing.

In Kenyatta National Hospital the number of patients with both essential and secondary hypertension is equally high, some patients are admitted already suffering the hypertension complications. Thus, it is of outmost importance that a solution is found in order to reduce the number of hypertensive patients developing hypertensive complications.

\subsection{Justification}

Hypertension associated complications are a major problem in the health care system because of their association with an increased risk of cardiovascular disease, stroke and coronary heart disease.

Statistics obtained from the Health Information System office in Kenyatta National Hospital indicates that the number of hypertensive patients rose from 880 in 2014 to 981 in 2015 , and in both years 252 patients succumbed to death associated with hypertension, it also indicates that, in 2015 between March and December there were 4519 newly diagnosed hypertensive patients in the outpatient clinic. In 2015, 1600 patients were admitted into the medical wards with hypertension, 619 had hypertension complications in terms of renal failure and heart disease.

Mortality and morbidity as a result of hypertension associated complications in Kenyatta National Hospital is a reality.

To my knowledge, no study has been done to assess the determinants of hypertension complications among adult hypertensive patients admitted in medical wards in $\mathrm{KNH}$.

\subsection{Objectives}

The broad objective was to identify the determinants of hypertension complications among adult hypertensive patients admitted in medical wards at Kenyatta National Hospital.

The Specific objectives

- To assess the demographic factors associated with hypertension complications among adult hypertensive patients admitted in medical wards at $\mathrm{KNH}$.

- To establish the socio-economic status of adult hypertensive patients admitted in medical wards inKNH

- To assess the health factors associated with hypertension complications among adult hypertensive patients admitted in medical wards in $\mathrm{KNH}$.

- To find out patients' level of awareness, disposition and life style practices that influence the occurrence of hypertension complication among adult hypertensive patients admitted in medical wards in $\mathrm{KNH}$.

\section{Methodology}

A mixed method (qualitative and quantitative) descriptive cross sectional study conducted at Kenyatta National Hospital's medical wards.
The study population consisted of hypertensive patients admitted in the medical wards.

The sample size was determined using Fisher's formula and a sample population of 80 obtained

The study instrument was pretested at Mbagathi sub county hospital which is located in Nairobi Kibra constituency.

Simple random sampling was used to ensure that there is a fair selection of the study participants to fill in the questionnaires while purposive sampling was used for key informants' interviews and focused group discussions.

Two medical doctors and five ward nurse in-charge were recruited to participate in the key informant's interview. Two focused group discussions involving six and seven hypertensive patients were conducted.

Data was entered and analyzed using Statistical Package of Social Sciences (SPSS) version 20, and data on the closed ended questions was coded manually by the researcher. Descriptive and analytical statistics was used to analyze data at a confidence interval of $95 \%$.

The analyzed data was presented in the form of tables and figures.

$\mathrm{KNH}$ being the country's referral hospital, the findings may be extrapolated to other hypertensive patients within the county and nation at large.

Clearance and approval to conduct the study was sought from The University of Nairobi- Kenyatta National Hospital Ethics and Research Committee. Participants gave a signed, voluntary informed consent prior to participation and were briefed on their rights and the expected benefits of the study.

\section{Literature Review}

The recommended blood pressure targets are $<140 / 90$ $\mathrm{mmHg}$ in uncomplicated patients with hypertension. [1-2].

Globally, nearly one billion adult people, equivalent to one-quarter of the world's adult population had hypertension in the year 2000, and this is estimated to increase to 1.56 billion (29\%) by 2025 [3].Hypertension complications prevalence data in Kenya is inadequate in availability. Hypertension is an important risk factor for brain infarction and hemorrhage and the incidence of stroke rises progressively with increasing blood pressure levels. This therefore, means that treatment of hypertension decreases the incidence of stroke. [4]. Hypertensive heart disease is as a result of structural and functional adaptations of the heart and over $30 \%$ of patients with sustained elevated blood pressure have left ventricular hypertrophy[5]

Hypertension is a risk factor for renal injury and end stage renal disease (ESRD) [6-7]. The renal risk appears to be more closely related to systolic blood pressure (SBP) than to diastolic blood pressure (DBP), and blacks are at greater risk than the whites for developing ESRD at every level of blood pressure.[8].A hypertensive crisis occurs when uncontrolled blood pressure spikes to extremely high levels, typically over $180 / 120 \mathrm{mmHg}$. This may cause bleeding in the lungs or brain, stroke, seizures, chest pain, heart attack or acute 
kidney failure. Chronic hypertension significantly raises the risk of a hypertensive crisis. The number of patients with hypertension complications is likely to grow as the population ages since either isolated systolic hypertension or combined systolic and diastolic hypertension occurs in the majority of persons older than 65. Advancement in age is a risk factor for high blood pressure [9]. On gender, Women are more likely to be aware of their status and to seek antihypertensive treatment than men [10]

Low socioeconomic status and poor access to health services and medications increases the vulnerability of developing major cardiovascular events due to uncontrolled hypertension. According to the WHO, more than $80 \%$ of deaths from uncontrolled hypertension and associated cardiovascular diseases now occur in low and middle-income countries, and this is common among people of low socioeconomic status $[2,11]$. Individuals consuming alcohol are at greater risk of developing cardiovascular diseases while those living with hypertension and are drinking alcohol, are even worse concerning the risk of developing cardiovascular pathology.

The World Health Organization in its strategies to reduce incidences of hypertension globally has recommended the reduction of alcohol consumption [12]. In addition, alcohol use and cigarette smoking also has been correlated with noncompliance to the treatment regimen [13]. Diet plays an important role in controlling blood pressure in hypertensive patients; reducing salt intake to less than $5 \mathrm{~g}$ per day has been correlated with proper control of blood pressure. Consumption of high fat diets leads to obesity and high body cholesterol level, this puts an individual at risk for developing atherosclerosis which increases blood pressure tenfold. Approximately one-third of hypertensive patients fail to maintain adequate follow-up schedules and half or more drop out of care within the first year of therapy. Moreover, $30 \%$ to $50 \%$ of patients have uncontrolled blood pressure [14]. Hypertensive clients who are knowleagable and informed on the condition can take active part in decision making and that the better knowledge the patients have, the better or, the higher the rate of compliance [15].

\section{Results}

\subsection{Demographic Characteristics}

Table 1. Cross tabulation of demographic factors and hypertension complications of hypertensive patients at KNH.

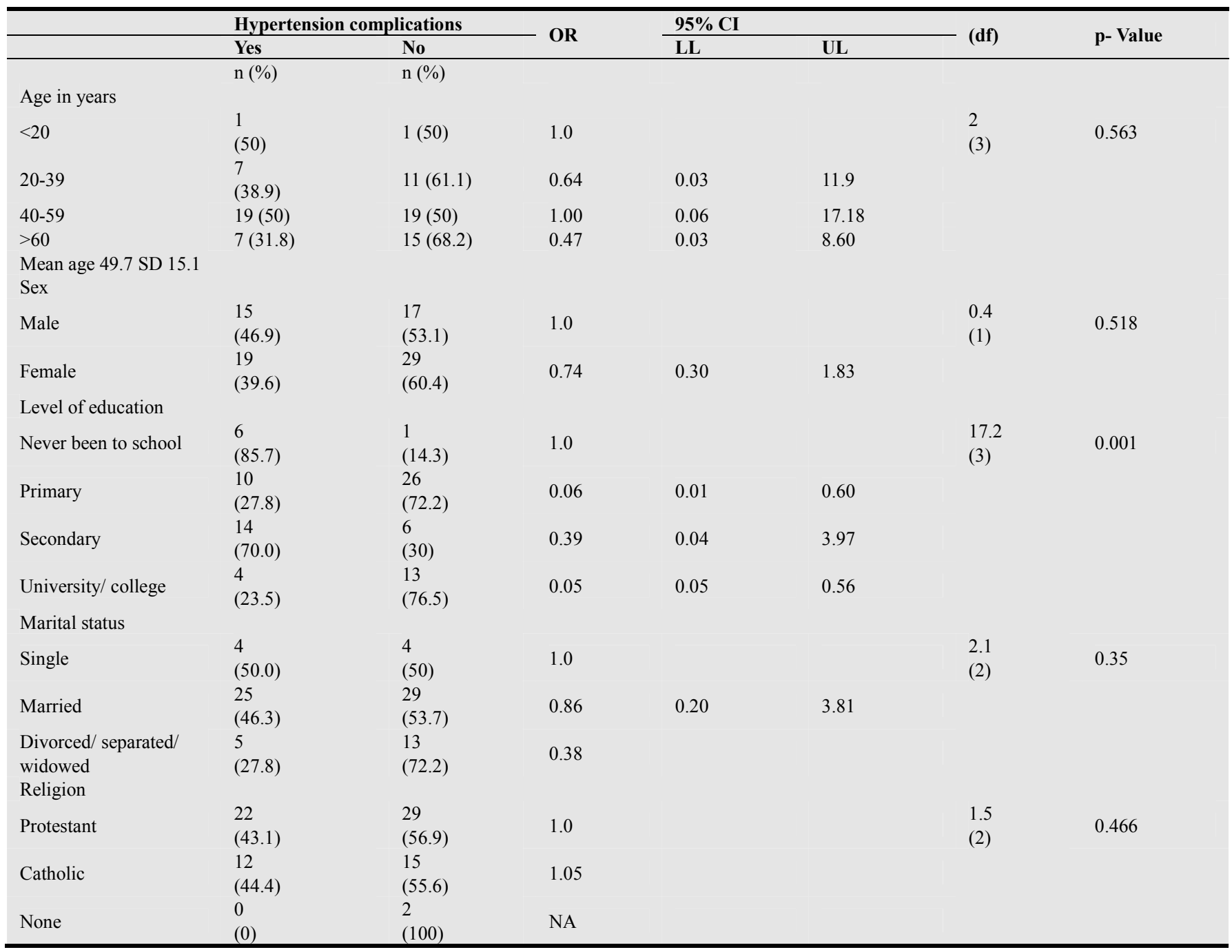


The mean age of hypertensive patients was 49.7 years (SD 15.1) with most patients being in the age groups $40-59$ years $38(47.5 \%)$ and over 60 years $22(27.5 \%)$. There were 32 (40\%) male and $48(60 \%)$ female hypertensive patients giving a male-to-female ratio of 2:3. Fifteen males and 19 females were already suffering hypertension complications.

On which gender is mostly affected Participant 2 in the second FGD

"Hypertensive men are more vulnerable to hypertension complications because they are the heads of the households and therefore bear all the responsibilities of the households, and the same is true in those households led by women but those affected are the women".

On causes of hypertension complications among hypertensive patients, participant 3 in the second FGD said;

"Hypertension complication is caused by stress; life in itself is stressful so to an individual who is already hypertensive stress contributes to occurrence of complications"

\section{Hypertension complications}

There were 34 patients who reported developing any complication related to hypertension yielding a prevalence of $42.5 \%$ (95\% CI 31.4-53.6\%) for hypertensive complications. Figure 1 shows the specific types of hypertensive complications that occurred. Kidney damage/ hypertensive nephropathy occurred in $18(22.5 \%)$ patients. The second most common complication associated with hypertension was blood vessel damage $8(10 \%)$ followed by brain damage 7 (8.8\%). There were no cases of hypertensive crisis.

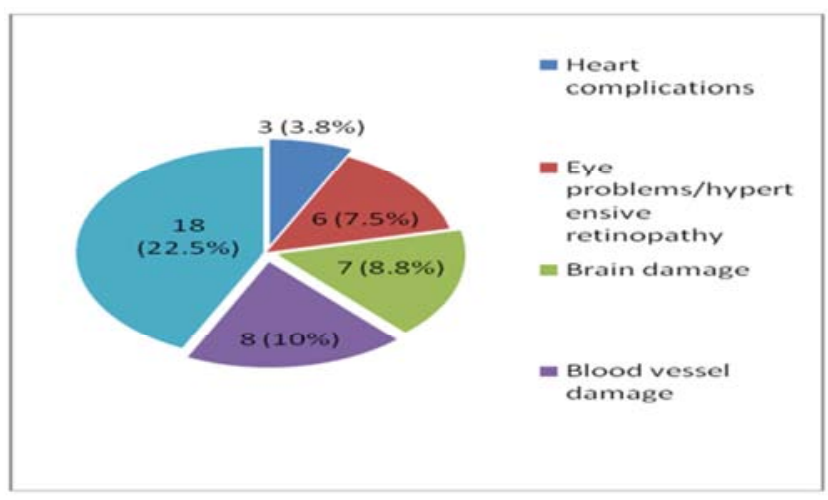

Figure 1. Hypertension complications among patients in KNH.

\subsection{Socioeconomic Factors and Hypertension Complications}

Overall, the hypertensive patients commonly reported that they were unemployed $35(43.8 \%)$, depended on medical insurance to pay for health services $44(55 \%)$ and did not have a hypertensive family member $43(53.8 \%)$, Table 2 . None of these socioeconomic attributes were significantly associated with development of hypertensive complications: employment status $(p=0.254)$, mode of payment for health services $(p=0.43)$ and positive family history of hypertension $(\mathrm{p}=0.137)$.

Table 2. Socio economic characteristics of hypertensive patients in $\mathrm{KNH}$.

\begin{tabular}{|c|c|c|c|c|c|c|}
\hline & \multirow{2}{*}{\multicolumn{2}{|c|}{ Total }} & \multicolumn{2}{|c|}{ Hypertension complications } & \multirow{2}{*}{ Chi (df) } & \multirow{2}{*}{$\begin{array}{l}P \\
\text { Value }\end{array}$} \\
\hline & & & Yes & No & & \\
\hline & $\mathrm{n}$ & $\%$ & $\begin{array}{l}\mathrm{n} \\
(\%)\end{array}$ & $\begin{array}{l}\mathrm{n} \\
(\%)\end{array}$ & & \\
\hline \multicolumn{7}{|c|}{ Employment status } \\
\hline Employed & 14 & 17.5 & $\begin{array}{l}6 \\
(42.9)\end{array}$ & $\begin{array}{l}8 \\
(57.1)\end{array}$ & $\begin{array}{l}4.1 \\
(3)\end{array}$ & 0.254 \\
\hline Unemployed & 35 & 43.8 & $\begin{array}{l}12 \\
(34.3)\end{array}$ & $\begin{array}{l}23 \\
(65.7)\end{array}$ & & \\
\hline Self employed & 29 & 36.3 & $\begin{array}{l}14 \\
(48.3)\end{array}$ & $\begin{array}{l}15 \\
(51.7)\end{array}$ & & \\
\hline Student & 2 & 2.5 & $\begin{array}{l}2 \\
(100)\end{array}$ & $\begin{array}{l}0 \\
(0.0)\end{array}$ & & \\
\hline \multicolumn{7}{|c|}{ Mode of payment for health services } \\
\hline Cash & 13 & 16.3 & $\begin{array}{l}8 \\
(61.5)\end{array}$ & $\begin{array}{l}5 \\
(38.5)\end{array}$ & $\begin{array}{l}2.8 \\
(3)\end{array}$ & 0.43 \\
\hline Insurance & 44 & 55 & $\begin{array}{l}16 \\
(36.4)\end{array}$ & $\begin{array}{l}28 \\
(63.6)\end{array}$ & & \\
\hline Well wishers & 20 & 25 & $\begin{array}{l}9 \\
(45.0)\end{array}$ & $\begin{array}{l}11 \\
(55.0)\end{array}$ & & \\
\hline Don't know & 3 & 3.8 & $\begin{array}{l}1 \\
(33.3)\end{array}$ & $\begin{array}{l}2 \\
(66.7)\end{array}$ & & \\
\hline \multicolumn{7}{|c|}{ Any hypertensive family member } \\
\hline Yes & 37 & 46.3 & $\begin{array}{l}19 \\
(51.4)\end{array}$ & $\begin{array}{l}18 \\
(48.6)\end{array}$ & $\begin{array}{l}2.2 \\
(1)\end{array}$ & 0.137 \\
\hline No & 43 & 53.8 & $\begin{array}{l}15 \\
(34.9)\end{array}$ & $\begin{array}{l}28 \\
(65.1)\end{array}$ & & \\
\hline
\end{tabular}


Table 3. Residence and distance to Health Facility.

\begin{tabular}{lll}
\hline Residence & $\mathbf{N}$ & $\mathbf{\%}$ \\
\hline Urban formal & 13 & 16.25 \\
Urban informal & 46 & 57.50 \\
Rural & 21 & 26.25 \\
Distance to health facility & & \\
Less than 5km & 65 & 81.25 \\
$5 \mathrm{~km}$ and above & 15 & 18.75 \\
\hline
\end{tabular}

In the FGD, all participants were for the opinion that finances play an important role in development of hypertension complications and most of them had acquired insurance covers since out of pocket payment for hospital bills is too expensive.

Participant 6 in the first FGD;

"Sometimes I fail to go for hospital clinic appointments and fail to buy my anti hypertensive drugs because I lack the money and when I have money I prefer to buy food for my children".

Fourth participant in first FGD

"Even if the drug costs 100 shillings, sometimes we lack even that amount to buy the drug."
On the role of social support in development of hypertension complications among hypertensive patients, $3^{\text {rd }}$ participant in second FGD said;

"Social support is an important factor in development of complications in the sense that it either encourages and motivates the patient positively or is a source of stress as it causes the hypertensive patient to despair and give up".

\subsection{Health Related Factors and Hypertension Complications}

There was a significant association between current systolic blood pressure and complication with 15 (60\%) of patients with current high readings presenting with complications compared to $19(34.5 \%)$ of those with normal readings $(\mathrm{p}=0.033)$.The risk of hypertensive complication increased 2.84 times $[\mathrm{OR}=2.84 ; 95 \%$ CI 1.07 $7.53(\mathrm{p}=0.033)]$ in clients with high systolic blood pressure compared to those with normal systolic blood pressure.

There was no significant correlation between BMI and both systolic (Pearson's rho -0.05) and diastolic (Pearson's rho-0.01) blood pressure.

Table 4. Cross tabulation of Health related factors and association with hypertension complications.

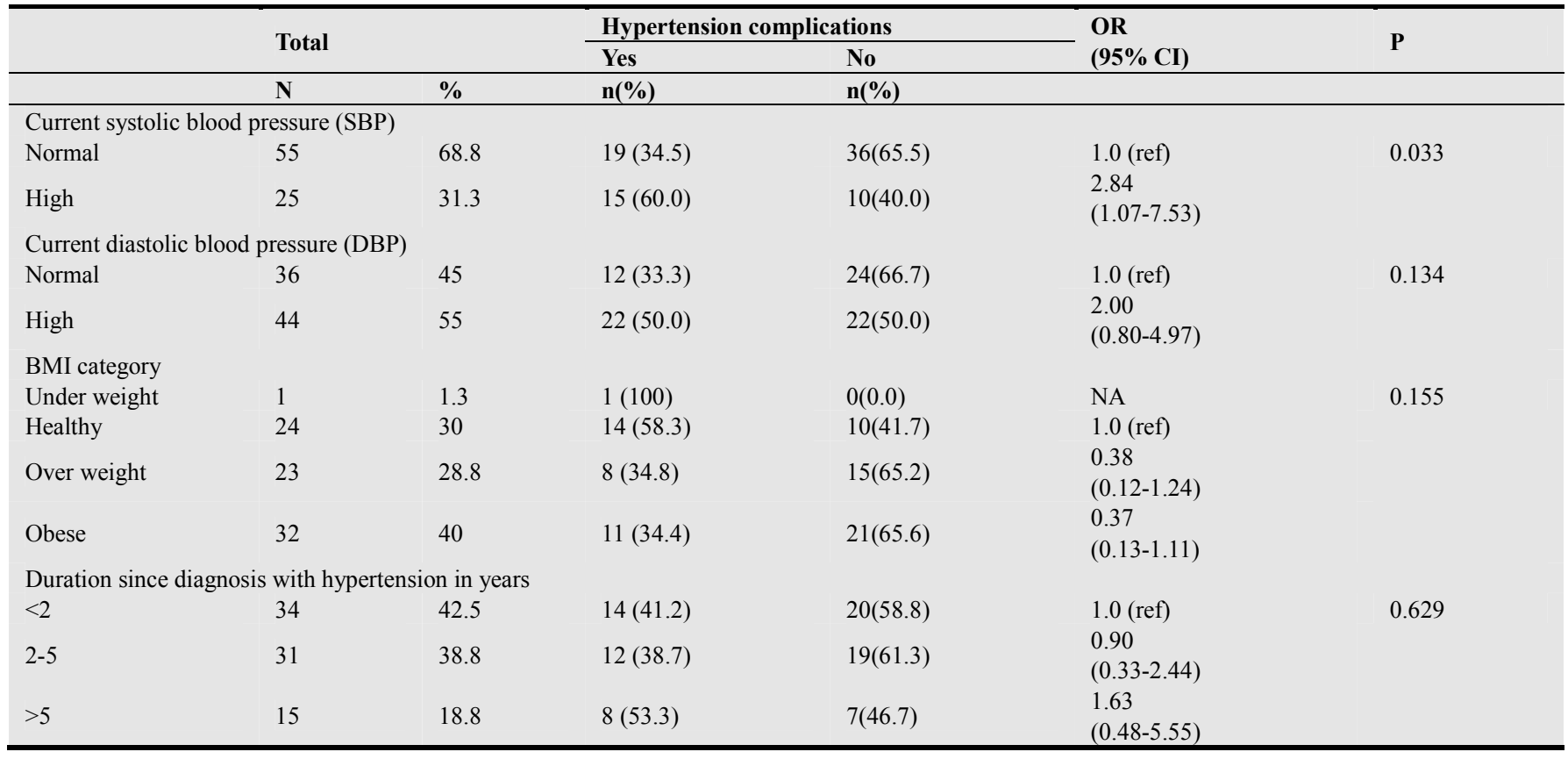

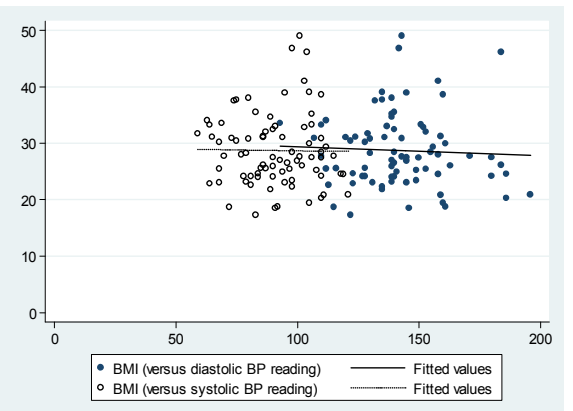

Figure 2. BMI versus $S B P$ and $D B P$ in hypertensive patients in $K N H$.
Pharmacological management of hypertension

All participants were on pharmacological management to control blood pressure, and $50(62.5 \%)$ were on treatment for other conditions like anti-coagulants, anti diabetic drugs, diuretics, asthmatic drugs, opiods, chemotherapy, antibiotics, and $\mathrm{H} 2$ receptor blockers, anti retroviral therapy (ARTs), anti-tuberculosis drugs and steroids apart from being on antihypertensive drugs. Most of the participants; $88.75 \%(71)$ self reported to be compliant to treatment and the $11.25 \%(9)$ who reported non compliance indicated the following reasons; financial constraint, forgetfulness, "to see if symptoms have abated" and when someone doesn't feel 
like the blood pressure is high.

Table 5. Pharmacological management of hypertension

\begin{tabular}{|c|c|c|c|c|c|c|}
\hline \multirow[t]{2}{*}{ Total } & & & \multicolumn{2}{|c|}{$\begin{array}{l}\text { Hypertension } \\
\text { complications }\end{array}$} & \multirow{2}{*}{$\begin{array}{l}\text { Chi } \\
\text { (df) }\end{array}$} & \multirow[t]{2}{*}{$\mathbf{P}$} \\
\hline & & & Yes & No & & \\
\hline & $\mathbf{n}$ & $\%$ & $n(\%)$ & $\mathbf{n}(\%)$ & & \\
\hline \multicolumn{7}{|c|}{ Taking antihypertensive medication as prescribed } \\
\hline Yes & 71 & 88.8 & $28(39.4)$ & $43(60.6)$ & $2.4(1)$ & 0.12 \\
\hline No & 9 & 11.3 & $6(66.7)$ & $3(33.3)$ & & \\
\hline \multicolumn{7}{|c|}{ Taking other medication } \\
\hline Yes & 50 & 62.5 & $22(44.0)$ & $28(56.0)$ & $0.1(1)$ & 0.726 \\
\hline No & 30 & 37.5 & $12(40.0)$ & $18(60.0)$ & & \\
\hline \multicolumn{7}{|c|}{ Experienced any side effects } \\
\hline Yes & 8 & 10 & $2(25.0)$ & $6(75.0)$ & $1.1(1)$ & 0.291 \\
\hline No & 72 & 90 & $32(44.4)$ & $40(55.6)$ & & \\
\hline
\end{tabular}

\subsection{Patients' Level of Awareness, Disposition and Life Style} Practices

Nearly half of the participants; $53 \%$ (43) were able to define hypertension correctly the rest didn't know or gave wrong definition, this is contrary to the fact that $98.75 \%$ (79)of the participants said that they were satisfied with the health information given to them by health workers on hypertension and its complications.

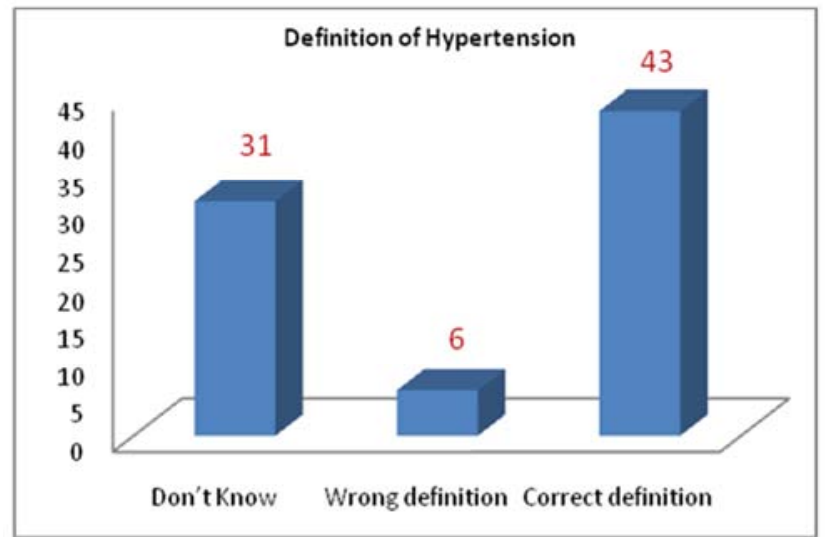

Figure 3. Definition of hypertension by hypertensive patients in $\mathrm{KNH}$.

Table 6. Patient lifestyle and its association with hypertension complications.

\begin{tabular}{|c|c|c|c|c|c|c|}
\hline & \multirow{2}{*}{\multicolumn{2}{|c|}{ Total }} & \multicolumn{2}{|c|}{$\begin{array}{l}\text { Hypertension } \\
\text { Complications }\end{array}$} & \multirow[t]{3}{*}{ Chi (df) } & \multirow[t]{3}{*}{$\mathbf{P}$} \\
\hline & & & Yes & No & & \\
\hline & $\mathbf{n}$ & $\%$ & $\mathbf{n}(\%)$ & $\mathrm{n}(\%)$ & & \\
\hline \multicolumn{7}{|c|}{ Advised by medical professional to change lifestyle } \\
\hline Yes & 29 & 36.3 & $16(55.2)$ & $13(44.8)$ & $3.0(1)$ & 0.084 \\
\hline No & 51 & 63.8 & $18(35.3)$ & $33(64.7)$ & & \\
\hline \multicolumn{7}{|c|}{ Ever been admitted for hypertension } \\
\hline Yes & 32 & 40 & $14(43.8)$ & $18(56.3)$ & $0.0(1)$ & 0.853 \\
\hline No & 48 & 60 & $20(41.7)$ & $28(58.3)$ & & \\
\hline \multicolumn{7}{|c|}{ Using family planning pills } \\
\hline \multirow[t]{2}{*}{ Yes } & 8 & 10 & $1(12.5)$ & $7(87.5)$ & $3.3(2)$ & 0.192 \\
\hline & & 50 & $18(45.0)$ & $22(55.0)$ & & \\
\hline Not applicable & 32 & 40 & $15(46.9)$ & $17(53.1)$ & & \\
\hline \multicolumn{7}{|l|}{ Cigarette smoker } \\
\hline Yes & 6 & 7.5 & $3(50.0)$ & $3(50.0)$ & $0.1(1)$ & 0.699 \\
\hline No & 74 & 92.5 & $31(41.9)$ & $43(58.1)$ & & \\
\hline \multicolumn{7}{|c|}{ Advised against smoking by medical professional } \\
\hline Yes & 24 & 30 & $12(50.0)$ & $12(50.0)$ & $0.8(1)$ & 0.374 \\
\hline No & 56 & 70 & $22(39.3)$ & $34(60.7)$ & & \\
\hline \multicolumn{7}{|c|}{ Exposed to indoor cigarette smoking } \\
\hline Yes & 11 & 13.8 & $7(63.6)$ & $4(36.4)$ & $2.3(1)$ & 0.127 \\
\hline No & 69 & 86.3 & $27(39.1)$ & $42(60.9)$ & & \\
\hline \multicolumn{7}{|c|}{ Amount of salt taken in food } \\
\hline No salt & 5 & 6.3 & $4(80.0)$ & $1(20.0)$ & $3.7(2)$ & 0.155 \\
\hline Low salt & 74 & 92.5 & $30(40.5)$ & $44(59.5)$ & & \\
\hline Too salty & 1 & 1.3 & $0(0.0)$ & $1(100)$ & & \\
\hline \multicolumn{7}{|c|}{ Alcohol consumption } \\
\hline Always & 6 & 7.5 & $3(50.0)$ & $3(50)$. & $2.7(2)$ & 0.254 \\
\hline Occasionally & 17 & 21.3 & $10(58.8)$ & $7(41.2)$ & & \\
\hline No & 57 & 71.3 & $21(36.8)$ & $36(63.2)$ & & \\
\hline \multicolumn{7}{|c|}{ Engaged in walking as physical activity } \\
\hline Yes & 69 & 86.3 & $30(43.5)$ & $39(56.5)$ & $0.2(1)$ & 0.658 \\
\hline No & 11 & 13.8 & $4(36.4)$ & $7(63.6)$ & & \\
\hline \multicolumn{7}{|c|}{ Engaged in heavy work } \\
\hline Yes & 21 & 26.3 & $11(52.4)$ & $10(47.6)$ & 1.1(1) & 0.286 \\
\hline No & 59 & 73.8 & $23(39.0)$ & $36(61.0)$ & & \\
\hline
\end{tabular}

The $5^{\text {th }}$ participant in the first FGD on smoking and alcohol said:

"I am currently being treated for kidney failure because I was not keen to comply to this hypertension treatment regimen, I used to drink alcohol and forget to go home and therefore didn't take my anti-hypertensive drugs. So not only 
did the alcohol make me not take this medications but also complicated my state".

\section{Compliance with lifestyle change}

Twenty one participants $(58.3 \%)$ reported that they rarely added salt to food had higher complication rates compared to those $13(29.5 \%)$ who never added salt to food $(p=0.01)$.

On causes of hypertension complications the first key informants said;
"Non-compliance is a very important cause of these hypertension complications and the reasons for noncompliance vary, some have inadequate knowledge, some experience side effects so they stop taking drugs, some have negative attitude towards the prolonged period of taking drugs, lack of supportive system and use of alternative medicine".

Table 7. Compliance with lifestyle changes.

\begin{tabular}{|c|c|c|c|c|c|c|c|}
\hline & & \multirow{2}{*}{\multicolumn{2}{|c|}{ Total }} & \multicolumn{2}{|c|}{ Hypertension complications } & \multirow{3}{*}{ Chi (df) } & \multirow{3}{*}{$\mathbf{P}$} \\
\hline & & & & Yes & No & & \\
\hline & & $\mathbf{N}$ & $\%$ & $\mathbf{n}(\%)$ & $\mathbf{n}(\%)$ & & \\
\hline \multirow[t]{4}{*}{ Smoking } & Daily & 1 & 1.3 & $1(100)$ & $0(0.0)$ & $3.6(3)$ & 0.313 \\
\hline & Frequently & 2 & 2.5 & $0(0.0)$ & $2(100)$ & & \\
\hline & Rarely & 3 & 3.8 & $2(66.7)$ & $1(33.3)$ & & \\
\hline & Never & 74 & 92.5 & $31(41.9)$ & $43(58.1)$ & & \\
\hline \multirow[t]{4}{*}{ Alcohol } & Daily & 1 & 1.3 & $1(100)$ & $0(0.0)$ & $3.9(3)$ & 0.269 \\
\hline & Frequently & 6 & 7.5 & $2(33.3)$ & $4(66.7)$ & & \\
\hline & Rarely & 15 & 18.8 & $9(60.0)$ & $6(40.0)$ & & \\
\hline & Never & 58 & 72.5 & $22(37.9)$ & $36(62.1)$ & & \\
\hline \multirow[t]{2}{*}{ Add salt to food } & Rarely & 36 & 45 & $21(58.3)$ & $15(41.7)$ & $6.7(1)$ & 0.01 \\
\hline & Never & 44 & 55 & $13(29.5)$ & & & \\
\hline \multirow[t]{3}{*}{ Physical exercise } & Daily & 1 & 1.3 & $0(0.0)$ & $1(100)$ & $1.2(2)$ & 0.545 \\
\hline & Frequently & 36 & 45 & $14(38.9)$ & $22(61.1)$ & & \\
\hline & Rarely & 43 & 53.8 & $20(46.5)$ & $23(53.5)$ & & \\
\hline \multirow[t]{4}{*}{ Enough sleep } & Daily & 6 & 7.5 & $1(16.7)$ & $5(83.3)$ & $2.6(3)$ & 0.458 \\
\hline & Frequently & 62 & 77.5 & $28(45.2)$ & $34(54.8)$ & & \\
\hline & Rarely & 11 & 13.8 & $5(45.5)$ & $6(54.5)$ & & \\
\hline & Never & 1 & 1.3 & $0(0.0)$ & $1(100)$ & & \\
\hline \multirow[t]{3}{*}{ Eat fruits and vegetable } & Daily & 30 & 37.5 & $13(43.3)$ & $17(56.7)$ & $0.8(2)$ & 0.678 \\
\hline & Frequently & 43 & 53.8 & $17(39.5)$ & $26(60.5)$ & & \\
\hline & Rarely & 7 & 8.8 & $4(57.1)$ & $3(42.9)$ & & \\
\hline \multirow[t]{4}{*}{ Take fatty food } & Daily & 2 & 2.5 & $1(50.0)$ & $1(50.0)$ & $1.0(3)$ & 0.81 \\
\hline & Frequently & 6 & 7.5 & $2(33.3)$ & $4(66.7)$ & & \\
\hline & Rarely & 61 & 76.3 & $25(41.0)$ & $36(59.0)$ & & \\
\hline & Never & 11 & 13.8 & $6(54.5)$ & $5(45.5)$ & & \\
\hline
\end{tabular}

\section{Discussion}

Level of education was significantly associated with hypertension complications $\mathrm{p}=0.001$, this is in line with a study done in Sudan, where uncontrolled blood pressure among $25 \%$ of subjects were illiterate, lack of BP control increased with increase in educational level [16].

Women are more likely to be aware of their status and to seek antihypertensive treatment than men [10] this is in line with this study where most participants $60 \%$ were females, and it was equally cited in the key informants' interview and focused group discussion.

Socio-economic factors are not independent predictors of hypertension complications but its significance is that it places patients in Kenya in the state of having to choose between competing priorities [17]. Most participants reported that they were unemployed $43.8 \%$ and there was no significant association between these and hypertension complications, this is inconsistent with the key informants interviews and FGD where it came out strongly that finances contribute to patients' non compliance to treatment. This is consistent with findings from a study which found out that several hypertensive patients self-reported that cost is a key barrier to both buying antihypertensive medications and seeing a physician, and therefore affect the effective control of BP and that free care improved DBP readings in lowincome patients with hypertension [18].

Some, $31.25 \%$ of participants had high systolic BP above $140 \mathrm{mmhg}$ which is significant especially because there is evidence that SBP is a important predictor of (cardiovascular) CVS and renal disease particularly in the elderly than DBP. 55\% had high diastolic BP above 90mmhg despite being on treatment. This is in line with a study done in $\mathrm{KNH}$ which indicated that only $26 \%$ of hypertensive patients on follow-up in the hospital's medical outpatient clinics had well-controlled blood pressure [19]. Therefore, just like the outpatients, the admitted hypertensive patients' level of blood pressure control is equally wanting The risk of developing cerebrovascular disorders and other complications is continuous, consistent and independent of other risk factor for all hypertensive persons. Strictly speaking, the higher the BP, the higher the risk of developing complications..

On compliance to lifestyle practices, most participants $(58.3 \%)$ reported rarely adding salt to food, and this was statistically significant $(\mathrm{p}=0.01)$ compared to those who never. The risk of hypertensive complications reduced by 
$70 \%$ in patients in patients who reported that they did not add salt to food compared to those who added salt to food. Studies indicate that indeed dietary salt reduction is an essential component of the non-pharmacological treatment of hypertension indicated strong associations between salt intake and hypertension.

\section{Conclusions}

This study provided evidence that level of education, financial constraints, high systolic blood pressure and diet especially addition of salt to food are associated with occurrence of hypertension complication.

Hypertension related complications are high in Kenyatta National Hospital with at least 34: 80hypertensive patient experiencing hypertension associated complication

Level of education is significantly associated with occurrence of hypertension complications with the illiterate participants experiencing the complicationsmore than those with higher education levels.

Financial constraints play a significant role in occurrence of hypertensive complications,participants reported that they lack the money to undertake the treatment regimen.

High systolic blood pressure is significantly associated with occurrence of hypertension complications.

Hypertension patients lack adequate knowledge on the condition and its treatment.

\section{Recommendations}

From the study results, blood pressure control statesof hypertensive in medical patients in $\mathrm{KNH}$ is uncontrolled, this predisposes patients to hypertension related complications.

Participants self report that they are satisfied with the health education given to them by health workers but a high percentage still lack the knowledge on the basic issues about their condition. Knowledge on hypertension complication is equally inadequate therefore there is need to promote individualized knowledge of hypertensive patients according to their unique needs, not only on hypertension but also hypertension complications and importance of prevention of those complications.

Hypertensive patients should be encouraged to take up insurance covers so that they are able to seek medical attention when the need arises without fear of paying out of pocket or not being able to pay.

Follow up system should be strengthened so that the hypertensive patients can be traced to prevent patients coming to hospital already suffering complications and so as to control the blood pressures of the hypertensive patients.

Hypertensive patients should be encouraged to change their lifestyle practices to prevent these complications by eating low salt diets and not adding salt to food since this is significantly associated with occurrence of hypertension complications.

More research studies should be carried out to specifically identify ways to prevent occurrence of hypertension complications among patients in $\mathrm{KNH}$ as developing countries continue experiencing epidemiological transition of non communicable diseases and especially in kenya where data is scarce.

\section{References}

[1] Muntner P, Krousel-Wood Met al., "New medication adherence scale versus pharmacy fill rates in seniors with hypertension." American Journal, 2009; 15(1): 59 -66.

[2] Chobanian A. V, Bakris G, et al., "The Seventh Report of the Joint National Committee on Prevention, Detection, Evaluation, and Treatment of High Blood Pressure: the JNC 7 report." JAMA, 2003: 289(19): 2560-2572.

[3] Kearney P, Reynolds K, Whelton P, He J, "Worldwide prevalence of hypertension: a systematic review." J Hypertens 2004; 22: 11-19.

[4] Loscalzo, J, Anthony S, Braunwald G, Eugene; Dennis L, et al. Harrison's principles of internal medicine. 2008, McGrawHill Medical.

[5] Steinmetz M, "Cardiac sequelae of hypertension." Der Internist in German, 2009; 50(4): 397-409.

[6] Krzesinski J, "Hypertension and the kidney."ActaClinicaBelgica, 2007; 62(1): 5-14.

[7] Krzesinski J, "Hypertension and the kidney."ActaClinicaBelgica. 2007; 62(1): 5-14.

[8] Lindhorst J, Blinggnaut J \& Rayner B, "Differences in hypertension between blacks and whites: an overview." Cardiovascular Journal of Africa, 2007; 18(4): 241 - 247.

[9] Staessen J, Gasowski J, Wang J, Thijs L et al., "Risks of untreated and treated isolated systolic hypertension in the elderly: meta-analysis of outcome trials." The Lancet. 2000; 355(9207): 865-872.

https://www.thelancet.com/journals/lancet/article/PIISO1406736(99)07330-4/abstract.

[10] Van de Vijver Set al., "Prevalence, awareness, treatment and control of hypertension among slum dwellers in Nairobi, Kenya." Journal of hypertension, 2013; 31(5): 1018-1024.

[11] Boutayeb A, "The double burden of communicable and noncommunicable diseases in developing countries." Transactions of the Royal Society of Tropical Medicine and Hygiene, 2006; 100(3): 191-199.

[12] WHO, "World Health Organisation; Global Health Estimates for hypertension." Health Information. Geneva. 2014. https://www.who.int/nmh/publications/wha resolution53 14/e $\mathrm{n} /$ Accessed on $20^{\text {th }}$ May 2016

[13] KyngasA\&Shamsul A, "Why hypertensive patients do not comply with their treatment: A case control study in Perlis Malasya."International Medical Journal, 2012: 19(1).

[14] Dunbar-Hill M, Miller N \& DeGeest S, "Adherence and persistence with taking medications to control high blood pressure." Journal of the American Society of Hypertension, 2011; 5(1): 56-63.

[15] Li W, "Hypertension control, predictors for medication adherence and gender differences in older Chinese immigrants." Journal of Advanced Nursing, 2008; 61(3): 326-335. 
[16] Babiker F. A, Lamia A. E \& Moukhyer M. E, "Awareness of hypertension and factors associated with uncontrolled hypertension in Sudanese adults." Cardiovascular Journal of Africa, 2013; 24(6): 208 - 212. https://doi.org/10.5830/CVJA2013-035

[17] Kopczy'nski J, Wojtyniak B \& Gorynski Z "The future of chronic diseases." Cent Eur J Public Health, 2001; 9(1): 3-13.
[18] Shulman N, Brogan D, Carr A \& Miles C. "Financial cost as an obstacle to hypertension Therapy." American Journal of Public Health, 2012; 76(1): 1105-1108.

[19] Achieng' L, Joshi E, Ogola N \& Karari E, "Adequacy of blood pressure control and level of adherence with antihypertensive therapy.' 'East African Medical Journal, 2009; 86(11): 499506. 